See discussions, stats, and author profiles for this publication at: https://www.researchgate.net/publication/7545745

\title{
Sources of Social Support as Predictors of Health, Psychological Well-Being and Life Satisfaction Among Dutch Male and Female Dual-Earners
}

Article in Women \& Health · February 2005

DOI: 10.1300/J013v41n02_04 · Source: PubMed

CITATIONS

62

3 authors, including:

Kk Sanders

UNSW Sydney

225 PUBLICATIONS 3,863 CITATIONS

SEE PROFILE

Some of the authors of this publication are also working on these related projects:

Leadership in SMEs View project

Project Innovative behaviour View project
READS

525

Tineke Willemsen

Leiden University

69 PUBLICATIONS 2,988 CITATIONS

SEE PROFILE 
This electronic prepublication version may contain typographical errors and may be missing artwork such as charts, photographs, etc. Pagination in later versions may differ from this copy; citation references to this material may be incorrect when this prepublication edition is replaced at a later date with the finalized version.

\title{
Sources of Social Support as Predictors of Health, Psychological Well-Being and Life Satisfaction Among Dutch Male and Female Dual-Earners
}

\author{
Geertje van Daalen \\ Karin Sanders \\ Tineke M. Willemsen
}

\begin{abstract}
We examined whether gender differences in health, psychological well-being, and life satisfaction, can be explained by effects of work-related and non-work related sources of social support. The sample consisted of 459 men and women from dual earner families. Men report better health and psychological well-being than women, whereas women report higher life satisfaction than men. Contrary to our expectations, women receive more social support from colleagues than men, while men and women equally receive support from their supervisor. As for the non-work related sources of social support, men receive more social support from their spouse, while women receive more social support from relatives and friends. No gender differences exist in the effects of social support. Although men and women differ with respect to the social support they receive from different sources, these differences cannot
\end{abstract}

Geertje van Daalen is affiliated with the Department of Human Resource Studies, Tilburg University. Karin Sanders is affiliated with the Department of Work and Organisational Psychology, Twente University. Tineke M. Willemsen is affiliated with the Department of Psychology, Tilburg University, Tilburg, The Netherlands.

Address correspondence to: Geertje van Daalen, Department of Human Resource Studies, Tilburg University, Warandelaan 2, PO Box 90153, 5000 LE Tilburg, The Netherlands (E-mail: G.vanDaalen@uvt.nl).

We gratefully thank Prof. Dr. G.L. Van Heck and Prof. Dr. A.J.J.M. Vingerhoets for making the data on the health monitor available for this study

Journal of Women \& Health, Vol. 41(2) 2005

Available online at http://www.haworthpress.com/web/WH

(C) 2005 by The Haworth Press, Inc. All rights reserved.

Digital Object Identifier: 10.1300/J013v41n02_04 
explain gender differences in health, psychological well-being and life satisfaction. [Article copies available for a fee from The Haworth Document Delivery Service: 1-800-HAWORTH. E-mail address: <docdelivery@haworthpress.com> Website: <http://www.HaworthPress.com> (c) 2005 by The Haworth Press, Inc. All rights reserved.]

The present study builds on and extends prior research on the beneficial effect of social support on health, well-being and life satisfaction. In particular, it focuses on the importance of different sources of social support for working men and women. Previous research showed that social support plays an important role in promoting health and well-being (Kaufmann \& Beehr, 1989; Sarason, Sarason, \& Pierce, 1990).

Social support can originate from different sources. Generally a distinction is made between work and non-work related sources of social support (King, Mattimore, King \& Adams, 1995; Adams, King, \& King, 1996). Work-related sources of social support refer to social support from supervisor and coworkers. Non-work related sources refer to extra-organizational sources, such as spouse, family, relatives, and friends. With the increase of women's labor force participation, more women can receive social support from work-related and non-work related sources.

Nevertheless, working women in the Netherlands and other European countries, report more health complaints than men, particularly stress-related illness and fatigue (LISV, 2001; Paoli \& Merllié, 2001). Moreover, working women are more likely to report absences (Paoli \& Merllié, 2001), and in the Netherlands they even make up the fastest growing medical category of people pronounced unfit for work (LISV, 2001). This raises the question why working (Dutch) women report more health complaints than working men and why working women more frequently become incapacitated for work than men. Women may report more health complaints because they experience less social support or social support from different sources than men.

Another explanation for the gender differences in health has to do with combining multiple roles. Most dual-earners combine multiple roles, however, women more frequently do so as they continue to be responsible for domestic and childcare activities regardless of their employment status (Gjerdingen, McGovern, Bekker, Lundberg, \& Willemsen, 2000; Lennon, 1994). However, research exploring the effects of combining multiple roles on health and well-being has shown inconclusive results (Gutek, Repetti, \& Silver, 1988; Lambert, 1990), as it focused largely on within-sex differences among women (Barnett \& 
Marshall, 1992; Kinnunen, Vermulst, Gerris, \& Mäkikangas, 2003), paid less attention to men (Barnett, Marshall, \& Pleck, 1992; Gove \& Zeiss, 1987) and seldom compared working men with working women (Nordenmark, 2002). Therefore, we do not know whether having multiple roles differently affects men and women. In the present study, we compare working women with working men and try to explain the expected health differences between working men and women through differences in sources of social support and the effect of social support on their health. Hence we hypothesize as follows:

Hypothesis 1: Working men will report better health (a) psychological well-being (b) and higher life satisfaction (c) than working women.

\section{SOCIAL SUPPORT}

Social support can be best defined as a complex transactional process in which an active interplay between a person and his or her support network is involved (Vaux, 1988). It includes providing empathy, caring, love and trust (emotional support), actual aid in time, money and energy (instrumental support), evaluative feedback (appraisal support), and information, advice and suggestions (informational support) (House, 1981).

Although results on the mechanisms through which social support influences health and well-being are inconclusive (Ganster, Fusilier, \& Mayes, 1986; Gore, 1981; House, 1981; Kaufmann \& Beehr, 1986; Kessler, Price, \& Wortman, 1985; Leavy, 1983; Thoits, 1982), social support is supposed to have a positive effect on one's health and well-being (Kaufmann \& Beehr, 1989; Sarason, Sarason, \& Pierce, 1990).

One can receive social support from various sources from different life domains. Furthermore, a distinction can be made between the different sources of support used by men and women, i.e., work-related and non-work related sources of social support. In general, women report more support from relatives and friends and rely less heavily on social support from their spouse than men (Belle, 1987; Ogus, Greenglass, \& Burke, 1990; Olsen \& Shultz, 1994; Vaux, 1985). Men report more support from their spouse (Reevy \& Maslach, 2001). Taylor et al. (2000) supposed that these gender differences in social support are a consequence of the different responses to stress situations by men and 
women. They state that men are more likely to fight-or-flight in stress situations, whereas women are more likely to tend-and-befriend, i.e. “. . . in response to stress situations, women show patterns involving caring for offspring, joining social groups to reduce vulnerability, and contributing to the development of social groupings, especially those involving female networks, for the exchange of resources and responsibilities" (Taylor, et al., 2000, pp. 421-422).

With regard to support from work-related sources, results are inconclusive. Various studies argue that employed men mostly rely on workrelated sources of support, whereas employed women rely on family or non-work related sources (Baruch, Biener, \& Barnett 1987; Etzion; 1984, Leavy; 1983). However, other studies report different or even opposite results. For instance, a study by Fusilier, Ganster and Mayes (1986), showed that support from family and friends was virtually unrelated to life-satisfaction for women, but showed a positive relationship for men. Similarly, support from family and friends was unrelated to depression in women, but was negatively related to depression in men.

Although women's labor force participation has increased, in the Netherlands most working women spend fewer hours per week on the job than working men (SCP, 2002). Working women, therefore, may have fewer opportunities to invest in social relationships at work and may as a consequence receive less social support from these relationships at work. As research findings on gender differences regarding social support received from work-related sources are inconclusive, we assume that gender differences regarding the number of hours men and women are engaged in work are related to gender differences in work-related sources of social support. Because women work on average fewer hours than men on the job (SCP, 2002) we expect that men receive more social support from work-related sources (supervisor and colleagues) than women. We hypothesize as follows:

Hypothesis $2 a$ : Working men will report more social support from supervisor than working women

Hypothesis $2 b$ : Working men will report more social support from colleagues than working women.

With regard to the gender differences in social support from nonwork related sources, we again hold time engaged in work responsible. That is, men are able to receive more support from their spouse as women work fewer hours on the job than men. Since most working women work fewer hours on the job than their spouse, generally, they 
spend more time on domestic activities such as housekeeping and childcare. Domestic activities can be interpreted as a practical form of social support. Men, on the contrary, generally spend more time working on the job, and have less time to provide their spouse with support. We hypothesize as follows:

Hypothesis 3a: Working men will report more social support from their spouse than working women.

Hypothesis $3 b$ : Working women will report more social support from their relatives and friends than working men.

Findings of previous research have shown that social support has a beneficial effect for both men and women (House, 1981; Leavy, 1983). Therefore, we expect that the different sources of support will have the same effect for men and women. Accordingly, we hypothesize as follows:

Hypothesis 4: Social support from supervisor, colleagues, spouse, and relatives and friends will have a positive effect on working men's and women's health (a) psychological well-being (b) and life satisfaction (c).

\section{HEALTH AND PERSONAL CHARACTERISTICS}

Both situational and personal characteristics appear to be important in respect to one's health and well-being (Houkes, 2002). Neuroticism refers to individual differences in the perception of negative emotions and self-concept (Watson, Clark, \& Tellingen, 1988). It predisposes persons to experience a moderately stable lower level of subjective well-being (e.g., Costa \& McCrae, 1980). Women have been found by some to have a higher average level of neuroticism than men (Heaven \& Shochet, 1995; Lynn \& Martin, 1997) this personal characteristic should be taken into account in a study regarding gender differences in health, well-being and life satisfaction. Although women on the average report higher levels of neuroticism, we expect neuroticism to be harmful for the health of both men and women. Accordingly, for the present sample we hypothesize as follows:

Hypothesis 5: Women will report a higher level of neuroticism than men. 
Hypothesis 6: Neuroticism has a negative effect on men's and women's health (a), psychological well-being (b) and life satisfaction $(\mathrm{c})$.

\section{METHOD}

\section{Respondents and Procedure}

Data were obtained from a so-called telepanel; the CentERpanel, ${ }^{1}$ which consists of 2000 Dutch households. Members of this panel are requested to fill out a questionnaire at their home computers every week. Topics vary each week. Before entering the CentERpanel, participants agree with the conditions of the panel and give permission to use their data for research purposes. To be a member of the panel, one does not need to have a personal computer with access to the internet. A household without internet access is supplied with a so-called set-top box with which questionnaires can be filled out using a television screen as a monitor. Questionnaires for the present study were only sent to those panel members holding a paid job at the time of the survey $(n=1171)$. A total of 962 panel members returned the questionnaire (response rate $82 \%)$. To be included in the present study, respondents had to meet the following criteria; (1) be married or cohabiting and (2) have a spouse who was also employed at the time of the survey, i.e., they had to be part of a dual-earner relationship. Furthermore, if two or more panel members of the same household returned the questionnaire, the data of only one of these respondents were used to ensure that the data would not be biased by characteristics of the couple. Hence, in case of couple data we randomly removed equal numbers of male and female respondents from the sample.

A total of 459 respondents met these inclusion criteria. Participants received a small compensation for being member of the panel. The centERpanel is representative of the Dutch population, i.e., on average the panel has similar experiences and knowledge to the population in the Netherlands (http://www.uvt.nl/centerdata).

Of these 459 respondents, 278 were men and 181 were women. Respondents ranged in age from 22 to 64, with a mean age of 41 years (on average, men were 5 years older than women, 43 and 38 years, respectively). Sixty-three percent of the respondents had one or more children. In terms of educational attainment, most respondents (56\%) completed some form of secondary or higher vocational training, this characteristic 
did not differ by gender. On average respondents worked 36 hours per week. Women worked fewer hours per week than men, respectively 29 and 41 hours per week. Respondents held various occupations.

\section{Measures}

Health, Psychological Well-Being and Life Satisfaction. Health, psychological well-being and life satisfaction were measured with the Health State Scale developed by Van Heck and Vingerhoets (2001). ${ }^{2}$ Health refers to one's physical condition and was measured with 8 items. A sample items is: "To what extent did your physical health or emotional problems hinder you in your daily activities, such as walking, climbing stairs, get yourself dressed, taking a bath, going to the bathroom?" Response categories were (1) "not at all" to (5) a "great deal," or (1) "not at all true" to (5) "totally true," or (1) "never" to (5) "always." Cronbach's alpha for this scale was .86.

Psychological well-being refers to one's subjective well-being and was measured with 5-items. For each item, respondents could indicate how they felt during the last month. An sample item is: "Last month ... I felt somber and blue." Response categories were (1) "never" to (5) "always." Cronbach's alpha for this scale was .82 .

Life satisfaction refers to one's possibilities to satisfy one's needs and desires and to participate in activities that lead to personal growth and self-development and was measured with 5-items. An sample items is: "To what extent are you satisfied with the circumstances you live in?" Response categories were (1) "not that satisfied" to (5) "extremely satisfied," or, (1) "not at all" to (5) "very." The Cronbach alpha for this scale was .78.

Social support. Social support from one's spouse and social support from colleagues were measured by two 8-item scales developed by Parasuraman, Greenhaus and Granrose (1992). Both scales represent the four types of support as conceptualized by House (1981): emotional, instrumental, appraisal and informational support. For the present study two additional scales, measuring social support from one's relatives and friends, and social support from one's supervisor, were added. Sample items are "To what extent is/are your [ . . spouse/relatives/friends/colleagues/supervisor ... .] willing to listen to your problems?", "To what extent is/are your [...] concerned about your welfare?", "To what extent do/does your [. . .] provide you with information you need to do the things you want to do?" and "To what extent do/does your [. . .] praise you for your accomplishments?" Response categories were (1) "not at 
all" to (5) "a great deal." The scales of Parasuraman et al. (1992) were translated into Dutch using standard procedures (including back-translation into English). The Cronbach alpha for social support from one's spouse was .86 , from one's relatives and friends .87 , from colleagues .92 and for social support from one's supervisor .95 .

Neuroticism. Neuroticism was measured with the 5-item Emotional Stability Scale of the B5BBS-25 developed by Mervielde (1992). This scale consists of a set of bipolar markers to indicate one's emotional stability. Respondents could indicate which trait described them best.

Background variables: The background variables measured were gender $(0=$ male, $1=$ female $)$, age, education, number of children, number of working hours and number of working hours of the spouse. Age, number of children, number of working hours, and number of working hours of the spouse were measured as continues variables. Education was measured with one item with seven categories: (1) grade school, (2) preliminary vocational school, (3) grammar school, (4) secondary vocational training, (5) higher vocational training, (6) university, (7) other.

\section{Data Analysis}

Zero order correlations were computed to examine the general pattern of relations among the variables. One-way analyses of variance (ANOVA's) were used to test for gender differences concerning health, psychological well-being, life satisfaction, work-related and non-work related sources of social support and for neuroticism. A series of multiple regression analyses was performed to assess the effects of gender and social support on each dependent variable. For each dependent variable, a regression equation was estimated in which the background variables and neuroticism were entered as a block at Step 1. At Step 2, the social support variables were entered as a block into the equation. To examine if neuroticism, the background variables and the sources of social support differently affect men's and women's health, psychological well-being and life satisfaction (hypothesis 4 and 5), at Step 3, the interaction effects between gender and neuroticism, gender and background variables, and gender and sources of social support were entered as a block into the equation. To eliminate non-essential correlation between the interaction terms and their component variables, all predictor variables were centered (Aiken \& West, 1991). To assess the model fit in each step the change is $R^{2}$ was tested. All analyses were cross-sectional. 


\section{RESULTS}

The means, standard deviations and correlations among study variables are displayed in Table 1. Gender was related to all the outcome variables, as well as to three of the four sources of social support. The sources of social support were positively related to one another. Most sources of support were positively related to psychological well-being and life satisfaction. Social support from supervisor was the only source of support that showed a significant relation with health. The outcome variables were related positively with one another. As expected, neuroticism showed negative relations with all the outcome variables and the sources of social support, except for the relation with social support from spouse.

\section{Gender differences}

Table 2 displays the means and standard deviations of men and women separately. Results of the ANOVA's for sex differences in health, psychological well-being, and life satisfaction showed that men reported better health $(F(1,458)=15.66, p<.01)$, and psychological well-being $(F(1,457)=22.48, p<.01)$ than women, confirming Hypotheses $1 \mathrm{a}$ and $1 \mathrm{~b}$. Women reported more life satisfaction than men $(F(1,457)=4.04, p<.05)$ contrary to Hypothesis $1 \mathrm{c}$.

With regard to the sources of social support and neuroticism, men and women did not report significantly different amounts of social support from supervisor $(F(1,457)=.08, n s)$. Women reported more social support from colleagues than men, $(F(1,457)=6.10, p<.05)$. Hypotheses $2 \mathrm{a}$ and $2 \mathrm{~b}$, expecting men to report more social support from their supervisor and colleagues, were not confirmed. Men reported more social support from their spouse than women $(F(1,457)=9.87, p<.01)$, whereas women reported more social support from relatives and friends $(F(1,457)=8.39, \mathrm{p}<.01)$, confirming hypotheses $3 \mathrm{a}$ and $3 \mathrm{~b}$. In accordance with hypothesis 5, women reported higher levels of neuroticism than men $(F(1,457)=13.11, p<.01)$.

\section{Results of the regression analyses}

Table 3 shows the results of the regression analyses for health, psychological well-being and life satisfaction, after controlling for gender, age, education, number of children, working hours, working hours of the spouse and neuroticism. 
TABLE 1. Means, Standard Deviations and Correlations amoung study variables

\begin{tabular}{|c|c|c|c|c|c|c|c|c|c|c|c|c|c|c|c|c|c|}
\hline & Variables & Mean & $S D$ & 1 & 2 & 3 & 4 & 5 & 6 & 7 & 8 & 9 & 10 & 11 & 12 & 13 & 14 \\
\hline 1 & Gender $(0=\mathrm{M}, 1=\mathrm{F})$ & .39 & .49 & 1.0 & & & & & & & & & & & & & \\
\hline 2 & Age & 40.86 & 8.79 & $-.28^{\star *}$ & 1.0 & & & & & & & & & & & & \\
\hline 3 & Education & 5.08 & 1.45 & -.00 & -.03 & 1.0 & & & & & & & & & & & \\
\hline 4 & Number of children & 1.23 & 1.10 & -.00 & .03 & $-.09^{*}$ & 1.0 & & & & & & & & & & \\
\hline 5 & Working hours & 35.95 & 10.99 & $-.55^{\star *}$ & $.14^{* *}$ & $.13^{* *}$ & $-.16^{* *}$ & 1.0 & & & & & & & & & \\
\hline 6 & Working hours spouse & 31.92 & 14.53 & $.64^{\star *}$ & $-.29^{* *}$ & .05 & $-.20^{\star *}$ & $-.29^{* *}$ & 1.0 & & & & & & & & \\
\hline 7 & Neuroticism & 3.30 & 1.20 & $.17^{* *}$ & $-.12^{*}$ & -.01 & .07 & $-.09^{*}$ & $.16^{\star *}$ & 1.0 & & & & & & & \\
\hline 8 & Social Support from Spouse & 3.68 & .73 & $-.15^{* *}$ & .01 & .05 & $-.17^{* *}$ & $.15^{* *}$ & -.01 & -.17 & 1.0 & & & & & & \\
\hline 9 & Social Support from Relatives \& Friends & 2.77 & .73 & $.13^{* *}$ & $-.20^{* *}$ & .09 & -.06 & $-.10^{*}$ & .09 & $-.12^{\star \star}$ & $.38^{* *}$ & 1.0 & & & & & \\
\hline 10 & Social Support from Colleagues & 3.23 & .76 & $.12^{*}$ & -.05 & .04 & .01 & $-.11^{*}$ & -.00 & $-.22^{\star *}$ & $.15^{\star \star}$ & $.29^{* *}$ & 1.0 & & & & \\
\hline 11 & Social support from Supervisor & 3.10 & .95 & -.01 & -.05 & -.03 & .04 & -.02 & .01 & $-.13^{\star \star}$ & .09 & $.22^{\star \star}$ & $.52^{\star \star}$ & 1.0 & & & \\
\hline 12 & Psychological Well-Being & 4.23 & .57 & $-.20^{* *}$ & $.11^{*}$ & -.03 & -.07 & $.13^{\star *}$ & $-.13^{\star *}$ & $-.40^{\star \star}$ & $.22^{\star \star}$ & -.02 & $.12^{\star *}$ & $.14^{\star *}$ & 1.0 & & \\
\hline 13 & Health & 4.19 & .63 & $-.18^{* *}$ & .02 & .01 & .00 & $.10^{*}$ & $-.13^{\star *}$ & $-.27^{\star \star}$ & .01 & -.01 & .08 & $.11^{*}$ & $.53^{\star *}$ & 1.0 & \\
\hline 14 & Life Satisfaction & 3.79 & .59 & $.09^{*}$ & .06 & .04 & -.07 & -.02 & .07 & $-.28^{* *}$ & $.37^{\star \star}$ & $.24^{\star \star}$ & $.23^{\star *}$ & $.15^{\star \star}$ & $.40^{\star *}$ & $.19^{\star \star}$ & 1.0 \\
\hline
\end{tabular}

Note: $\mathrm{N}=459,{ }^{*} \mathrm{p}<.05 ;{ }^{* *} \mathrm{p}<.01$ (two-tailed).

Note: correlations between the four sources of social support indicate that there is no multicollinearity problem in the data (see Tabachnick and Fidell, 2001). 
TABLE 2. Means (and standard deviations) for men and women separately.

\begin{tabular}{lcc}
\hline & $\begin{array}{c}\text { Men } \\
(\mathrm{N}=278)\end{array}$ & $\begin{array}{c}\text { Women } \\
(\mathrm{N}=181)\end{array}$ \\
\hline Health & $4.28(.58)$ & $4.05(.67)$ \\
Psychological Well-Being & $4.32(.53)$ & $4.09(.60)$ \\
Life Satisfaction & $3.75(.59)$ & $3.86(.59)$ \\
Social Support from Supervisor & $3.11(.92)$ & $3.08(1.0)$ \\
Social Support from Colleagues & $3.16(69)$ & $3.34(.86)$ \\
Social Support from Spouse & $3.77(.65)$ & $3.55(.81)$ \\
Social Support from Relatives and Friends & $2.70(.67)$ & $2.90(.81)$ \\
Neuroticism & $3.14(1.18)$ & $3.55(1.18)$ \\
\hline
\end{tabular}

\section{Health}

Neuroticism was significantly related to health $(\beta=-.30, p<.01)$. None of the background variables, and none of the four social support variables were significant predictors. Moreover, no significant interaction effects were observed for gender and the background variables, indicating that the sources of social support and the background variables were not differentially important for men and women. This confirms hypothesis 4a.

As shown in Table 3, neuroticism explained the largest proportion of the variability associated with health $\left(R^{2}=.10\right)$. None of the four social support variables explained a significant portion of the variability associated with health $\left(\Delta R^{2}=.01, \mathrm{~ns}\right)$, after controlling for neuroticism and the background variables. The proportion of additional variance explained by the interaction terms, after controlling for neuroticism, the background and social support variables in the model, was not significant $\left(\Delta R^{2}=.02, \mathrm{~ns}\right)$.

\section{Psychological Well-Being}

Only neuroticism was significantly related to psychological well-being $(\beta=-.35, p<.01)$. None of the background variables and also none of the four social support variables were significant predictors. The effect of social support from spouse was just below the level of significant $(\beta=.13, p=.06)$. The interaction effect of gender by working hours of the spouse was significantly related to psychological well-being $(\beta=$ 
TABLE 3. Sources of Social Support as Predictors of Health, Psychological Well-Being and Life Satisfaction

\begin{tabular}{|c|c|c|c|c|c|c|c|}
\hline & \multirow[b]{2}{*}{ Variable } & \multicolumn{2}{|c|}{ Health } & \multicolumn{2}{|c|}{ Psychological Well-Being } & \multicolumn{2}{|c|}{ Life Satisfaction } \\
\hline & & $\beta$ & $\Delta \mathrm{R} 2$ & $\beta$ & $\Delta \mathrm{R} 2$ & $\beta$ & $\Delta \mathrm{R} 2$ \\
\hline \multirow[t]{3}{*}{ Step 1} & Control variables and Neuroticism & & $.10^{* \star}$ & & $.18^{\star *}$ & & $.11^{\star *}$ \\
\hline & Control variables a & & & & & & \\
\hline & Neuroticism & $-.30^{* *}$ & & $-.35^{\star \star}$ & & $-.30^{\star *}$ & \\
\hline \multirow[t]{5}{*}{ Step 2} & Sources of Social Support & & .01 & & $.03^{\star \star}$ & & $.13^{\star \star}$ \\
\hline & Support from Spouse & -.02 & & $.13 \ddagger$ & & $29^{\star \star}$ & \\
\hline & Support from Relatives and Friends & -.07 & & -.11 & & -.01 & \\
\hline & Support from Colleagues & -.06 & & .04 & & .06 & \\
\hline & Support from Supervisor & .07 & & .08 & & 11 & \\
\hline \multirow[t]{9}{*}{ Step 3} & Interactions & & .02 & & .01 & & .02 \\
\hline & Neuroticismªender & .07 & & -.01 & & .10 & \\
\hline & Working hours*Gender & -.20 & & -.13 & & .08 & \\
\hline & Working hours Spouse ${ }^{*}$ Gender & -.14 & & $-.41^{*}$ & & $-.36^{*}$ & \\
\hline & Support Spouse ${ }^{*}$ Gender & -.05 & & .11 & & .02 & \\
\hline & Support Relatives and Friends*Gender & .05 & & .01 & & .11 & \\
\hline & Support Colleagues*Gender & .12 & & -.06 & & .00 & \\
\hline & Support Supervisor*Gender & -.00 & & .05 & & -.07 & \\
\hline & $R^{2}$ & & .12 & & .22 & & .26 \\
\hline
\end{tabular}

a Gender, age, education, number of children, working hours and working hours spouse were included in Step 1 but are not shown. Standardized regression coefficients (beta-weights) 
$-.41, p<.05)$, indicating that this background variable was differentially important for men and women. Men's psychological well-being was better as the number of working hours of their spouse was higher. Women, on the other hand, had a lower level of psychological well-being if their spouse's number of working hours was larger. Sources of social support did not differ by gender, confirming hypothesis $4 \mathrm{~b}$.

As shown in Table 3, the four social support variables explained a significant though small portion of the variability associated with psychological well-being $\left(\Delta R^{2}=.03, p<.01\right)$, after controlling for neuroticism and the background variables. The proportion of additional variance explained by the interaction terms, after controlling for neuroticism, the background and social support variables in the model, was not significant $\left(\Delta R^{2}=.01, n s\right)$.

\section{Life Satisfaction}

Age and neuroticism were significantly related to life satisfaction $(\beta=-.10, p<.05)$ and $(\beta=-.30, p<.01)$. Of the social support variables, only social support from spouse was a significant predictor $(\beta=$ $.29, p<.01)$. The interaction effect of gender by working hours of the spouse was significantly related to life satisfaction $(\beta=-.36, p<.05)$, indicating that this background variable had different effects for men and women. Men's life satisfaction was higher as their spouses worked more hours, whereas women's life satisfaction was lower as their spouses worked more hours. Sources of social support did not differ by gender, confirming Hypothesis 4c.

As shown in Table 3, the background variables and neuroticism explained a significant portion of the variance in life satisfaction $\left(R^{2}=\right.$ .11). $\mathrm{R}^{2}$ changed significantly to $13 \%$ due to the social support variables being entered into the equation. The proportion of additional variance explained by the interaction terms, after controlling for neuroticism and the background and social support variables in the model, was not significant $\left(\Delta R^{2}=.02, \mathrm{~ns}\right)$.

\section{Neuroticism}

No interaction effects were found for neuroticism and gender in each of the regression analyses. Hypothesis $6 \mathrm{a}, \mathrm{b}$ and $\mathrm{c}$, stating that neuroticism has a negative effect on men's and women's health, psychological well-being and life satisfaction, therefore was confirmed. 


\section{DISCUSSION}

In the present study, we examined gender differences in health, psychological well-being, life satisfaction, sources of social support, and neuroticism. Furthermore, we examined gender differences concerning the effects of work-related and non-work related sources of social support on health, psychological well-being and life satisfaction.

Gender differences regarding health and psychological well-being were as expected, that is, men reported better health and psychological well-being than women. For life satisfaction, gender differences were opposite to what we expected, that is, women reported higher life satisfaction than men. The gender differences found for work-related sources of social support were contrary to what we expected. Namely, men did not report more social support from supervisor and from colleagues than women; instead women reported more social support from colleagues than men. The gender differences that were found for the non-work related sources of social support were as expected and in line with Olsen and Shultz (1994), Reevy and Maslach, (2001) and Vaux (1985). We found, with respect to one's health, psychological well-being and life satisfaction, that men and women equally benefit from work-related and non-work related sources of social support. Women report higher levels of neuroticism. However, neuroticism equally affected men's and women's health, psychological well-being and life satisfaction.

An explanation for the fact that working women, despite worse health and psychological well-being than working men, report higher life satisfaction may be that working on the job provides women with more opportunities for development, economical independence, social contacts, and therefore leads to a more meaningful life, which increases one's life satisfaction (Barnett, 1994; Geurts, Taris, Demerouti, Dikkers, \& Kompier, 2002).

That women report more social support from colleagues than men, may be because women seek more intimate relationships than men (Belle, 1987; Ogus, Greenglass, \& Burke, 1990). It may also be, in line with Taylor et al., (2000), that women on the job contribute more frequently than men to the development of social grouping to exchange resources and responsibilities, and therefore receive more social support from this source. Furthermore, in line with Ibarra (1992) it may be that women have more multiplex ties to the members of their social networks, i.e., colleagues are not only colleagues but are also friends. 
Although men and women differed with regard to the sources of social support they received, these differences did not explain the gender differences in health, psychological well-being and life satisfaction, as no significant gender by sources of social support interactions were observed. The gender differences that occurred concerned the working hours of one's spouse. We found that more total working hours of men were associated with diminished psychological well-being and life satisfaction of women, whereas more total working hours of women were associated with an enhanced level of psychological well-being and life satisfaction of men. In accordance with role strain theory, we assume that, as men work longer hours, women will perform most domestic and care activities, and hence more often carry the burden of combining multiple roles. A possible explanation for men's greater psychological well-being and life satisfaction if women work longer hours may be that this leads to more financial resources which can be used for buying care (Barnett, 1982; Bird \& Bird, 1986). So, in general, women do not benefit if the total working hours of their spouses increase, whereas men do benefit from an increase in the total working hours of their spouses. These findings are contrary to that of Stolzenberg (2001), who found that if men worked more hours this had no detrimental effects on women's health, and if women worked more than 40 hours per week this had substantial negative effects on men's health. An explanation for these differences may be that most women in the Netherlands work part time; only very few work more than 40 hours per week, ${ }^{3}$ whereas in the study by Stolzenberg detrimental health effects for men were found for women who worked more than 40 hours per week. Furthermore, although most women in the Netherlands work part time and carry out most domestic and care activities, it may be that they expect their spouses also to do their share at home and if men work more hours they have less time to do so.

Another explanation may be the fact that in the Netherlands flexible work time arrangements, such as working part time are very common. Although our sample is representative of the Dutch population, the possibility to generalize from our results may be more difficult, especially in countries where such flexible work time arrangements are not common.

It is remarkable that of all the variables, neuroticism appears to be the strongest predictor of health, and psychological well-being. Social support from spouse and neuroticism were nearly equally strong related to life satisfaction. Although women reported higher levels of neuroticism, neuroticism equally affected men's and women's health, 
psychological well-being and life satisfaction, as we observed no significant gender by neuroticism interactions. For both men and women neuroticism had a negative effect on their health, psychological well-being and life satisfaction.

It seems that one's spouse was the most important significant other in one's life, with respect to health and life satisfaction, as social support from spouse was the only significant predictor of life satisfaction and psychological well-being both for men and women. The other sources of social support were not significantly related to life satisfaction and psychological well-being. A possible explanation may be cross-over effects for non-work related social support, i.e., social support from spouse may be beneficial for coping with work-related problems.

Some limitations and issues for future research should be noted. One limitation of the present study is that it does not include type of work. It may be that the results of the present study are affected because we did not distinguish between different types of work. Some types of work, e.g., health care and education, may be more harmful to one's health than others. It may be that, especially, different networks characterize these types of work, e.g., in health care most employees are female, therefore networks exist for the largest part of female members, whereas in technical industry male members dominate networks. Another limitation, related to the first one, has to do with work pressure. Work pressure is different for each type of work; as a consequence, building a network may be affected and hence dissimilar for people in different jobs. A third limitation, that is also work-related, deals with the degree of interdependency, i.e., to what extent is one dependent on others in doing one's job successfully. Interdependency may lead to enhanced vulnerability to health complaints, as successfully accomplishing one's job lies beyond one's control (e.g., Merllié \& Paoli, 2001).

Fourth, considering the fact that men and women's psychological well-being and life satisfaction were affected by the working hours of the spouse, in a sample consisting of respondents who are part of a dual-earner couple, it would be very useful to examine 'couple' or 'paired response' data in future research. Studying 'couple' data might be an opportunity to compare husbands and wives, but also to get insight into how decisions made by one of them, influences the other.

To better understand the role of social support in relation to health, psychological well-being and life satisfaction, it is important in future research to consider work characteristics that may affect one's social network. Because gender differences in social support did not explain gender differences in health, psychological well-being and life satisfac- 
tion, future research should examine coping styles other than social support that are effective in reducing role strain. Furthermore, future research should further explore the role of social support from spouse as well as crossover-effects from work and non-work related domains of life, as findings of the present study showed that only social support from spouse significantly affected psychological well-being and life satisfaction.

\section{NOTES}

1. For detailed information on the CentERpanel see http://www.uvt.nl/centerdata/ en/whatwedo/thecenterpanel/

2. The full questionnaire can be obtained from the corresponding author.

3. In our study only 18 male respondents indicated that their spouse was working more than 40 hours per week.

\section{REFERENCES}

Adams, G. A., King, L. A., \& King, D. W. (1996). Relationships of job and family involvement, family social support, and work-family conflict with job and life satisfaction. Journal of Applied Psychology, 81, 411-420.

Aiken, L. S., \& West, S. G. (1991). Multiple regression: Testing and interpreting interactions. Newbury Park, CA: Sage Publications.

Barnett, R. C. (1982). Multiple roles, gender, and psychological distress. In L. Goldberger \& S. Breznitz (eds.), Handbook of stress: Theoretical and clinical aspects (second edition), pp 427-445. New York: Free Press.

Barnett, R. C. (1994). Home-to-work spillover revised: a study of full-time employed women in dual-earner couples. Journal of Marriage and the Family, 56, 647-656.

Barnett, R. C., \& Marshall, N. L.(1992). Men's job and partner roles: Spillover effects and psychological distress. Sex Roles, 27, 455-472.

Barnett, R. C., Marshall, N. L., \& Pleck, J. H. (1992). Men's multiple roles and their relationship to men's psychological distress. Journal of Marriage and the Family, 54, 358-367.

Baruch, G. K., Biener, L., \& Barnett, R. C. (1987). Women and gender in research on work and family stress. American Psychologist, 48, 130-136.

Belle, D. (1987). Gender differences in the social moderators of stress. In R. C. Barnett, L. Biener, \& G. K. Baruch (Eds.), Gender and stress (pp. 257-277). New York: Free Press.

Bird, G. W., \& Bird, G. A. (1986).Strategies for reducing role strain among dual-career couples. International Journal of the Sociology of the Family, 16, 83-94.

Costa, P. T., Jr., \& McCrae, R. R. (1980). Influence of extraversion and neuroticism on subjective well-being: Happy and unhappy people. Journal of Personality and Social Psychology, 38 (4), 668-678. 
Etzion, D. (1984). Moderating effect of social support on the stress-burnout relationship. Journal of Applied Psychology, 69, 615-622.

Fusilier, M. R., Ganster, D. C., \& Mayes, B. T. (1986). The social support and health relationship: Is there a gender difference? Journal of Occupational Psychology, 59, 145-153.

Ganster, D. C., Fusilier, M. R., \& Mayes, B. T. (1986). Role of social support in the experience of stress at work. Journal of Applied Psychology, 71, 102-110.

Geurts, S. A. E., Taris, T. W., Demerouti, E., Dikkers, J., \& Kompier, M. A. J. (2002). Waar werk en prive elkaar raken: de stand van zaken [Where work and nonwork meet: The state of the art]. Gedrag en Organisatie, 15(3), 163-183.

Gjerdingen, D., McGovern, P., Bekker, M., Lundberg, U., \& Willemsen, T. M. (2000). Women's work roles and their impact on health, well-being and career: Comparisons between the United States, Sweden, and the Netherlands. Women \& Health, 31, 1-20.

Gore, S. (1981). Stress-buffering functions of social supports: An appraisal and clarification of research models. In B. S. Dohrenwend \& B. P. Dohrenwend (Eds.), Stress life events and their contexts (pp. 202-222). New York: Prodist.

Gove, W.R., \& Zeiss, C. (1987) Multiple roles and happiness. In F. Crosby (ed.), Spouse, parent, worker: On gender and multiple roles. New Haven, CT: Yale University Press.

Gutek, B. A., Repetti, R. L., \& Silver, D. (1988). Nonwork roles and stress at work. In C.L. Cooper \& R. Payne (eds.), Causes, coping and consequences of stress at work (pp. 141-174). New York: Wiley.

Heaven, P. C. L. \& Shochet, I. M. (1995). Dimensions of neuroticism: Relationships with gender and personality traits. Personality and Individual Differences, 18 (1), 33-37.

Houkes, I. (2002) Work and individual determinants of intrinsic work motivation, emotional exhaustion and turnover intention. A study among bank employees and teachers. Dissertation from University of Maastricht. Maastricht, The Netherlands: Datawyse.

House, J. S. (1981). Work stress and social support. MA: Addison-Wesley, Reading.

Ibarra, H. (1992). Homophily and differential returns: Sex differences in network structure and access in an advertising firm. Administrative Science Quarterly, 37, 422-447.

Kaufmann, G. M., \& Beehr, T. A. (1986). Interactions between job stressors and social support: Some counterintuitive results. Journal of Applied Psychology, 71, 522-526.

Kaufmann, G. M., \& Beehr, T. A. (1989). Occupational stressors, individual strains, and social support among police officers. Human Relations, 42, 185-197.

Kessler, R. C., Price, R. H., \& Wortman, C. B. (1985). Social factors in psychopathology: Stress, social support, and coping processes. Annual Review of Psychology, 36, 631-572.

King, L. A., Mattimore, L. K., King, D. W., \& Adams, G. A. (1995). Family supportive inventory for workers: A new measurement of perceived social support from family members. Journal of Organizational Behavior, 16, 235-258.

Kinnunen, U., Vermulst, A., Gerris, J., \& Mäkikangas, A. (2003). Work-family conflict and its relations to well-being: the role of personality as a moderating factor. Personality and Individual Differences, 35, 1669-1683. 
Lambert, S. J. (1990). Processes linking work and family: A critical review and research agenda. Human Relations, 43, 239-257.

Leavy, R. L. (1983). Social support and psychological disorder: A review. Journal of Community Psychology, 11, 3-21.

Lennon, M. C. (1994). Women, work and well-being: The importance of work conditions. Journal of Health and Social Behavior, 35, 235-247.

LISV (2001). Ontwikkeling arbeidsongeschiktheid jaaroverzicht WAO/WAZ/Wajong 2000 [Development of incapacity for work]. Amsterdam: Landelijk instituut sociale verzekeringen (LISV).

Lynn, R., \& Martin, T. (1997). Gender differences in extraversion, neuroticism, and psychoticism in 37 nations. The Journal of Social Psychology, 137 (3), 369-373.

Merllié, D., \& Paoli, P. (2001). Ten years of working conditions in the European union: Summary. Dublin, Ireland: European Science Foundation.

Mervielde, I. (1992). The B5BBS-25: A Flemish set of bipolar markers for the "Big-Five" personality factors. Psychologica Belgica, 32, 195-210.

Nordenmark, M. (2002). Multiple social roles-a resource or a burden: Is it possible for men and women to combine paid work with family life in a satisfactory way? Gender, Work and Organization, 9 (2), 125-145.

Ogus, E. D., Greenglass, E. R., \& Burke, R. J. (1990). Gender-role differences, work stress and depersonalisation. Journal of Social Behavior and Personality, 5, 387-398.

Olsen, D. A., \& Shultz, K. S. (1994). Gender differences in dimensionality of social support. Journal of Applied Psychology, 24, 1221-1232.

Paoli, P., \& Merllié, D. (2001). Third European survey on working conditions 2000. European Foundation for the Improvement and Living and Working Conditions. Luxembourg: Office for Official Publications of the European Communities.

Parasuraman. S., Greenhaus. J. H., \& Granrose, C. S. (1992). Role stressors, social support, and well-being among two-career couples. Journal of Organizational Behavior, 13, 339-356.

Reevy, G. M., \& Maslach, C. (2001). Use of social support: Gender and personality differences. Sex Roles, 44, 437-459.

Sarason, B. R., Sarason, I. G., \& Pierce, G. R. (1990) Traditional views of social support and their impact on assessment. In B. R. Sarason, I. G. Sarason, \& G. R. Pierce (Eds.), Social support: An interactional view (pp. 9-25). New York: Wiley.

SCP (2002). Emancipatie monitor 2002 [Emancipation monitor 2002]. The Hague, The Netherlands: Sociaal en cultureel planbureau (SCP).

Stolzenberg, R.M. (2001). It's about time and gender: Spousal employment and health. American Journal of Sociology, 107 (1), 61-100.

Tabachnick, B. G. \& Fidell, L.S. (2001). Using multivariate statistics. Boston, Allyn and Bacon.

Taylor, S. E., Cousino Klein, L., Lewis, B. P., Gruenewald, T. L., Gurung, R. A. R., \& Updegraff, J. A. (2000). Biobehavioral responses to stress in females: Tendand-befriend, not fight-or-flight. Psychological Review, 107, 411-429.

Thoits, P. A. (1982). Conceptual, methodological, and theoretical problems in studying social support as a buffer against life stress. Journal of Health and Social Behavior, 23, 145-159. 
Van Heck, G. L., \& Vingerhoets, A. J. J. M., (2001). Gezondheidsmonitor [Health Monitor]. Tilburg, The Netherlands: CenterData.

Vaux, A. (1985). Variations in social support associated with gender, ethnicity, and age. Journal of Social Issues, 41, 89-110.

Vaux, A. (1988). Social support: Theory, research and intervention. New York: Praeger.

Watson, D., Clark, L. A., \& Tellegen, A. (1988). Development and validation of brief measures of positive and negative affect: The PANAS scales. Journal of Personality and Social Psychology, 54, 1063-1070. 